\title{
Dança e os meios de comunicação de massa
}

\section{Dance and the mass media}

Rafael Guarato ${ }^{1}$ 


\section{Resumo}

Este trabalho consiste em revisitar correntes teóricas que examinaram relações entre arte, cultura e indústria cultural, com intuito de analisar sua pertinência em investigações sobre manifestações dançantes. Tal exercício se faz plausível frente à complexidade das relações de produção e consumo, que ampliam as opções e possibilidades de decisão dos usuários/consumidores em nosso tempo, exigindo a necessidade de reavaliar a viabilidade de premissas apresentadas por intelectuais como Theodor W. Adorno, Max Horkheimer e Walter Benjamin à luz da antropologia e dos estudos culturais.

Palavras-chave: Dança; apropriação; usos; indústria cultural

\section{Abstract}

This text is to revisit theoretical currents that examined relationships between art, culture and cultural industries, in order to analyze their relevance in investigations about media dancing demonstrations. Such exercise is made plausible forward the complexity of the relations of production and consumption that expand options and decision possibilities of users / consumers in our time, requiring the need to reassess the feasibility of assumptions presented by intellectuals such as Adorno, Max Horkheimer and Walter Benjamin in the light of anthropology and cultural studies.

Keywords: Dance; appropriation; uses; cultural industry
ISSN: 1414.5731

E-ISSN: 2358.6958 
Ainda neste momento, considerável parte dos estudos sobre dança realizados no Brasil tem concentrado seus esforços em dois grandes eixos norteadores: de um lado, os pesquisadores que se dedicam à análise de artistas e obras legitimadas ou pleiteadoras do estatuto de arte; de outro, estudiosos que se debruçam sobre fazeres corporais da chamada "cultura popular", empenhados no endosso constante de alguma "essência" quase misteriosa que permite a seu objeto ser reconhecido também como merecedor de elogios e volteios. Por vezes, mas não raro, são desenvolvidas investigações que se arriscam a borrar as modernas fronteiras entre dança como arte e dança como não-arte.

Esse panorama grosseiramente apresentado me causa a impressão de que o norte das preocupações dos pesquisadores brasileiros sobre dança, até agora, tem sido o de justificar a importância de seus objetos, seja para a sociedade, por esta não acolher a dança como as outras artes; para o poder público como meio de instrumentalizar debates sobre a importância da dança na sociedade - logo, a necessidade de programas estatais de fomento à dança; ou para o meio acadêmico, no qual a área ainda dá seus primeiros passos. Diante de tal diagnóstico, mesmo que genérico, arrisco-me a afirmar que a "autenticidade" das danças populares e o grau de "complexificação" da dança como arte têm oferecido âncoras para tais justificativas. O que é comum a ambas as frentes de análise é a recusa veemente em atribuir valor (cultural ou artístico) às danças que se fazem presentes nos meios de comunicação de massa e que desfrutam de uma indústria cultural.

Tal recusa se faz, ora por negligência ao assunto - detectável principalmente nos estudos sobre cultura popular (Côrtes, 2000; Katz, 1989; Monteiro, 2011; Rodrigues, 2005; Santos, 1996; Silva, 2012) - ora por meio de diferentes formas de explicitar a rejeição das danças presentes na mídia por pesquisadores dedicados à dança na condição de arte (Gallardo e Sborquia, 2002; Katz, 2009; Souza, 2004; Tomazzoni, 2009; Marques, 2010). De modo sintético, as acusações sobre as danças midiáticas respaldam seus argumentos em dois grandes pilares: a) são danças dedicadas ao mercado e não à criação artística ou de valores culturais tradicionais; b) lidam com uma forma de funcionamento que se pauta na reprodução, alijando processos de reflexão e autonomia crítica dos sujeitos que as praticam.

No meu entendimento, esse modo de conceber a dança presente nos meios massivos dispõe de um manancial teórico rastreável, posto em evidência nas últimas décadas da primeira metade do século XX pela teoria crítica alemã. Visto isso, meu objetivo neste artigo é duplo. Em primeiro lugar, discutir premissas de intelectuais e seus pressupostos que foram alicerce da formulação do conceito de indústria cultural (aqui, peço paciência aos já iniciados nessas leituras), relacionando tais concepções com as encontradas em estudos sobre dança no Brasil. Em segundo lugar, analisar a viabilidade dos preceitos que balizam a negligência/rejeição de práticas dançantes existentes nos meios massivos de comunicação, recorrendo a estudos antropológicos e culturais. Caso consiga persuadir meus leitores dos valores das danças midiáticas, teremos então outras possibilidades de lançar novos olhares sobre elas e seus fazedores.

No momento histórico em que os elementos culturais passaram a ser exibidos e consumidos em grande escala, surgiu um grupo de pensadores que se dedicou 
à análise desse processo. A corrente de pensamento ficou conhecida como "teoria crítica" da famosa Frankfurter Schule (Escola de Frankfurt), na qual se destacaram os pensadores Theodor W. Adorno, Walter Benjamin, Herbert Marcuse e Max Horkheimer, que se dedicaram a examinar o papel da cultura e da arte frente à nova situação social provinda do capitalismo avançado, quando as técnicas de reprodução e comercialização alcançaram os bens culturais.

Entre os teóricos da Escola de Frankfurt havia divergências de opinião. Walter Benjamin, por exemplo, defendia que a arte pode servir como instrumento tanto de entretenimento quanto para a ação política. Argumentava que sempre existiu a reprodução da obra de arte, sendo que a única diferença se encontra no fato de que, no início do século XX, esse processo passou a ser realizado em série, o que não significa que a obra de arte perdeu sua autenticidade, pois, "em sua essência, a obra de arte sempre foi reprodutível. $O$ que os homens faziam sempre podia ser imitado por outros homens" (Benjamin, 1994, p. 166). Para Benjamin, a alteração promovida pelo capitalismo foi a de fazer com que a obra de arte perdesse seu valor de culto e, em contrapartida, ganhasse maior valor de exibição, fator decisivo para a conquista da autonomia do artista.

Posta nesses termos, a modificação não consiste apenas numa simples exploração dos bens culturais por parte dos meios e da indústria, mas, antes, de uma modificação estrutural no modo de funcionamento do campo artístico e das condições de sobrevivência monetária do artista. O dilema nos é apresentado pelo filósofo Rafael Cordeiro Silva (2006) nas seguintes palavras: "Sob esse aspecto, o artista não é mais o protegido do rei ou dos papas, para os quais ele produz, mas depende agora da aceitação de sua arte, ele tem diante de si o imperativo da sobrevivência por meio da arte" (Silva, 2006, p. 26). Fruto desse processo, emerge um paradoxo: se, por um lado, a arte ganha autonomia, dando liberdade à criação do artista, por outro, lida com o mercado, que passa a regular a autonomia estética, pois, para vender suas obras e sobreviver, o artista depende da aceitação pública.

Caminhando por outra via explicativa e contradizendo a concepção de Benjamin, Theodor Adorno e Max Horkheimer criaram o termo "indústria cultural" para designar tanto uma modificação no sentido da arte como a fusão entre arte "inferior" (popular) e "superior" (erudita) e o comércio de ambas quanto uma extensão da racionalidade técnica para a cultura com o objetivo de dominação social, tornando-se, na concepção dos autores, a maior forma de dominação do capitalismo avançado². O corolário da industrialização de bens culturais se encontraria exclusivamente na efetivação de interesses comerciais de um grupo específico, os detentores dos veículos de comunicação, ao passo que a sociedade se transformaria num mercado de consumo dos produtos, sempre impostos, culminando na massificação da cultura.

Adorno argumenta ser inadmissível a associação entre obra de arte e mercado, refutando a hipótese levantada por Benjamin. Empenhado em demonstrar a invalidade da cultura quando massificada, Adorno enfatiza que só a arte verdadeira possi-

2 Os textos nos quais aparece tal perspectiva são diversos, a exemplo de ADORNO, Theodor W; HORKHEIMER, Max. A indústria cultural: o esclarecimento como mistificação das massas. In: ___. Dialética do esclarecimento. Rio de Janeiro: Zahar, 1983, p. 99-138; ADORNO, Theodor W. O fetichismo na música e a regressão da audição. In: Os Pensadores. São Paulo: Nova Cultural, 1996; __ _. Indústria cultural e sociedade. São Paulo: Paz e Terra, 2002; __ . A indústria cultural. In: Gabriel Cohn (org.). Theodor Adorno: Sociologia. São Paulo: Ática, 1986, p. 92-99. (Coleção Grandes Cientistas Sociais, v. 54); HORKHEIMER, Max. Arte nuevo y cultura de masas. In: Teoría crítica. Barcelona: Barral, 1973, p. 115-137. 
bilita o conhecimento; o entretenimento não, porque causa desintegração do gosto e, especificamente com referência à música, provocaria uma "regressão da audição" (Adorno, 1996), entendida como a incapacidade de o ouvinte reconhecer a música e identificar-se com ela. Ao criticar a cultura de massas, analisando o fenômeno social da música, o autor se refere ao "fetichismo da mercadoria", resultado da padronização que desvaloriza os produtos culturais e torna a qualidade indiferente aos olhos dos apreciadores da arte. Para evidenciar suas premissas, ele exemplifica o processo ao acentuar que as músicas que mais fazem sucesso, independentemente de seu valor estético, são aquelas constantemente difundidas nos meios de comunicação.

Ao aprofundar esse tema, o filósofo alemão afirma que, como consequência da industrialização da cultura, os artistas "colocam-se a serviço do sucesso, renunciam ao impulso insubordinado e rebelde que lhes era próprio [ao mesmo tempo em que] o ouvinte se converte em simples comprador e consumidor passivo" (Adorno, 1996, p. 70). A preocupação de Adorno inclui o pressuposto de que, tratada como mercadoria, a arte corre o risco de perder sua autonomia, tornando-se refém do mercado. O perigo reside na fragilização estética da obra de arte, pois, ao buscar atender o mercado (o grande público), o produtor se submete ao gosto de uma audiência mediana e homogeneizada, moldando sua obra aos padrões populares. Sua forma deixaria de servir à crítica social para servir ao entretenimento.

É como se a audiência fosse enfeitiçada pelos produtos de massa. Tal formulação, que insiste em atribuir aos meios todo poder de domínio, restando aos sujeitos o lugar de passividade frente ao que lhes é exposto, é comungada por Max Horkheimer:

Lo que hoy en día se conoce con el nombre de entretenimiento popular, responde en realidad a una necesidad creada artificialmente por la industria de la cultura, manipulada por ella y, por consiguiente, depravada. Tiene muy poco que ver con el arte, y menos aún donde pretende selo. [...] en realidad nunca dependió directamente de las masas, sino de sus representantes en otras clases sociales (Horkheimer, 1973, p. 134-135).

São essas as premissas que também orientam as reflexões de Adorno quando se refere à televisão, entendida como instrumento de domínio da cultura de massa, procedendo por automatização de padrões, repetição de juízos e controle psicológico, resultando na criação de uma sociedade mediana, adepta e não questionadora das hierarquias e autoritarismos. Assim considerada, a televisão seria capaz de "manejar" o espectador por meio de um processo que consiste em "fixar padrões para os membros do público sem que eles tenham consciência disso" (Adorno, 1973, p. 554). "Passivo", "inconsciente", "manipulado": são esses os adjetivos da teoria crítica alemã para os sujeitos que consomem os produtos culturais veiculados massivamente.

Feita essa breve resenha, procedo à análise de como autores que escrevem sobre dança no Brasil tratam as manifestações corporais da dança presentes nos meios de comunicação de massa para que possamos notar a similitude com os pressupostos apresentados pelos teóricos alemães. Um estudo emblemático nesse caso foi realizado pelo coreógrafo e professor Airton Tomazzoni, que teve sua formação em dança atravessada por experiências midiáticas de filmes e video clips, mas que, ao desenvolver sua tese de doutorado em educação, cedeu à concepção de tratar as 
danças presentes na mídia como "estratégias de governamento" (Tomazzoni, 2009, p. 250). Para este autor, a mídia desenvolve as funções de ensinar e educar, mas sobrecarregada de aspectos pedagógicos não enunciados.

Ao enfatizar sua análise nos conteúdos veiculados e mantendo a perspectiva de que os meios detêm o poder sobre a informação, Tomazzoni perpetua a concepção de que o sujeito não possui escolha, restando-lhe consumir aquilo que lhe é ofertado. Todavia, os estudos dedicados a rejeitar de modo incisivo as danças presentes nos meios massivos são apresentados por autores cujas preocupações estão centradas em definir aspectos que permitem distinguir as danças como artes daquelas desprovidas dessa qualificação. Nesse processo, merecem destaque os textos voltados ao ensino de dança na educação formal.

A partir de meados da década de 1990, com o advento midiático de danças, a exemplo do samba duro baiano (também designado como swingueira) sob o rótulo de axé, de bondes de funk carioca até os mais recentes fenômenos, como dança dos famosos, arrocha e passinho nos meios de comunicação de massa, desfrutando de considerável exibição e popularidade frente à sociedade brasileira, retomaram-se discussões que tratam de bens culturais veiculados nesses meios como algo desprovido de conteúdo artístico ou de função social. Segundo tal modo de perceber a prática dançante nos meios massivos, a forma de exibição, os modos e técnicas de ensino, os movimentos executados, suas vestimentas e indumentárias características estão fadados ora à sugestão explícita de prática sexual, justificando discursos moralizadores, ora à desqualificação de seu fazer como dança.

O campo da dança como arte, ao lidar com regras específicas de operação, apressa-se em demarcar a distância. A crítica de dança Helena Katz (2009), em seu texto intitulado "A diferença entre arte e cultura", busca elucidar a importância da arte no cotidiano e sua capacidade de "estimular os nossos sentidos de maneira especial". Tentando suavizar seu discurso, a autora reconhece a existência de diferentes formas de arte, como, por exemplo, a "arte popular", destacando que a não compreensão das artes provém do não acesso a elas. No entanto, é emblemática em ressaltar que o acesso à arte é restrito, "pois as artes não estão, por exemplo, na televisão e nem no rádio [permanecendo certa] desconfiança de que a arte não é para todo mundo" (Katz, 2009, p. 3).

No meu entendimento, a preocupação de Katz é o de ressaltar o descaso com que os grandes veículos de comunicação de massa tratam as produções artísticas no Brasil. Contudo, não posso deixar de notar em seu discurso a negação da condição de arte às danças que existem e são veiculadas pelos grandes meios. Temos então declarado o reforço de uma das premissas básicas para a desqualificação das danças presentes nos meios: ela não é arte!

Seguindo a esteira de Katz, mas de modo menos cuidadoso, emergiram estudos cujos conteúdos são abundantes de preconceitos carregados de juízos de valor, empenhados não em examinar, mas, antes, em classificar e desqualificar as danças encontradas nos meios massivos. Preocupada com o ensino da dança, a pesquisadora Maria Inês Galvão Souza (2004), ao perceber a interferência dos meios de comunicação de massa e da indústria cultural no aprendizado corporal das crianças e jovens brasileiros, define as danças axé, funk e pagode como portadoras de um "vocabulário 
corporal restrito e pobre" [e com] "ausência de liberdade de criação e expressão dos corpos", inserindo o público dessas danças no lugar de receptor passivo, tendo em vista que este "fica submetido à reprodução de certos modelos" (Souza, 2004, p. 5).

Esse aspecto tendencioso, portador de verdades historicamente construídas sobre as relações entre dança e indústria cultural, não é exclusivo. Também analisando o ambiente escolar, os pesquisadores Gallardo e Sborquia (2002) se mostraram escandalizados ao se depararem com a prática corporal da dança funk nas escolas, afirmando que "a ascensão do gênero funk vem afrontar ainda mais a moralidade no país" (Gallardo e Sborquia, 2002, p. 111). Assim como Adorno e Horkheimer, Souza (2004) e Gallardo e Sborquia (2002) apontam as danças massificadas como um mal a ser combatido, recorrendo, para tanto, ao tratamento desmerecedor de credibilidade por meio da generalização e unicidade de interpretação sobre a prática corporal.

Ainda sobre o ensino de dança na escola, nenhum trabalho alcançou a robustez e popularidade dos de Isabel Marques (2010) ${ }^{3}$. Doutora em educação e pedagoga de formação, é hoje uma das autoras mais lidas nos estudos envolvendo dança e ensino 4 . Tendo em vista que uma crítica aprofundada das premissas de Marques ultrapassaria o escopo deste estudo - apesar de se fazer necessária tal empreitada -, ater-me-ei a apresentar como a autora edifica sua proposta pautada em maniqueísmos simplistas, construindo um mal a ser combatido para posteriormente apresentar sua proposta messiânica de ensino da dança na escola.

A autora anuncia, como objetivo central de seu estudo, conectar a dança ao mundo em que os dançantes vivem (Marques, 2010). No entanto, o conceito de dança trabalhado pela autora é o da dança entendida como arte, distante, assim, dos fazeres corporais dos setores populares. Em busca de subsidiar seus argumentos, Marques se ancora na pedagogia dialógica de Paulo Freire sobre a égide de impregnar as ações de sentidos como relação a ser estabelecida. Nesse ponto, a autora é cuidadosa em reforçar que não se trata de unilateralidade do professor oferecer os sentidos.

Todavia, ao desenvolver suas reflexões, Marques esconde, em sua teoria pedagógica, velhos padrões de legitimação, prestígio e seleção, ao construir a noção de sentido por meio da compreensão ampla das relações políticas, culturais e sociais que envolvem os sujeitos como aquela digna de ser reconhecida como ato significativo. Por esse ponto de vista, não fazer nada, reproduzir, dançar na "boquinha da garrafa" são tratados como atos não significativos, tendo em vista que o ato educacional de "impregnar de sentido" pressupõe releituras do cotidiano. Assim, parte-se da noção de que as pessoas desconhecem seus cotidianos ou que não os ressignificam enquanto participam das relações sociais. Vejamos como a autora se expressa:

Ler uma dança não é o mesmo que possuir habilidades corporais e técnicas específicas, vocabulário preciso ou o código padrão aprovado pelo senso comum para reproduzir coreografias prontas. Ler criticamente a dança - dançar, assistir, compor, pesquisar, produzir, ensinar - passa por outros caminhos que não o da memorização surda, da cópia inconsciente, da reprodução mecânica (Marques, 2010, p. 33).

\footnotetext{
3 Optei por utilizar a obra "Linguagem da dança: arte e ensino" por compreender que, nela, a autora condensa suas propostas anteriores e apresenta de modo mais detalhado sua perspectiva teórica.

4 Tal afirmação pode ser constatada pela recorrência dos textos de Marques nas bibliografias básicas dos cursos de licenciatura em dança existentes no país, assim como nos referenciais de pesquisadores sobre o assunto, disponíveis nos anais do Comitê Temático Mediações Educacionais da Associação Nacional de Pesquisadores em Dança (Anda).
} 
A diferença de Marques para os autores anteriormente apresentados consiste em que as danças classificadas sobre os juízos de "reprodução mecânica" ou "cópia inconsciente" vão desde o balé clássico ao hip hop, ou seja, não se limitam às danças presentes nos meios massivos. O inimigo declarado de Marques é o ensino técnico de dança, seja ela qual for. Essa estratégia discursiva da autora é compreensível quando entendemos que a principal definição de dança como arte se pauta naquilo que ela não é, ou seja, arte como aquilo que foge ao "pré-codificado" à "transmissão e execução de passos" (Marques, 2010, p. 40). Grosso modo, sua arte se faz calcada no desmerecimento de outras formas de fazer, visão simplista daquilo com o qual ela sugere se preocupar.

O que interessa aqui é reconhecer o quanto as premissas de Marques são tributárias da perspectiva teórica de Theodor Adorno e Max Horkheimer sobre os bens culturais, tendo-se que aceitar de pronto a premissa determinista de que a reprodução produz "máquinas", "simples executores de tarefas, passivos e sem iniciativa" (Marques, 2010, p. 50). Uma vez estabelecida a relação entre reprodução e ilegitimidade, a autora procede ao discurso apocalíptico sobre os meios massivos, aproveitando-se de uma perspectiva que possui coerência e ampla aceitação social no mundo acadêmico e fora dele.

Assim, as danças presentes na indústria cultural ganham o seguinte contorno: "aulas de dança alicerçadas pelas leis de mercado tendem a vender amostras das ondas passageiras da moda em suas salas (da lambaeróbica à dança de rua), impregnando de superficialidade até mesmo as propostas mais consistentes de dança" (Marques, 2010, p. 134). Com esse recurso, uma vez desmerecidas as formas de dança que possuem a técnica como um de seus suportes significativos principais, desqualificadas as maneiras de dançar que encontraram espaço midiático, a autora pôde então inserir a proposta pedagógica que acredita ser não apenas viável, mas necessária, frente à "superficialidade" existente.

O que aproxima os estudiosos de dança aqui elencados é uma reivindicação de autoridade etnográfica sobre aquilo do qual se fala, respaldado na empiria do próprio pesquisador. Esse procedimento é possível, pois, "precisamente porque é difícil pinçá-la, a 'experiência' tem servido como uma eficaz garantia de autoridade etnográfica" (Clifford, 2011, p. 36). Em nenhuma das pesquisas citadas houve abordagem e análise dos sujeitos que dançam nos meios massivos e que reproduzem passos. 0 que esses textos nos oferecem em termos de reflexões sobre essas danças e as pessoas que as praticam foram retirados de observação e relato, uma prática etnográfica característica da antropologia até as primeiras décadas do século passado, quando a observação associada ao conhecimento teórico era tida como requisito suficiente para classificar e determinar as ações humanas em sociedade.

Desconfio que tal fragilidade não resulta de despreparo, mas sim de um procedimento de poder estético e ilustrativo de uma retórica de persuasão, por meio da qual são geradas imagens discursivas sobre o que e como são essas danças, identificando-as como emotivas, imitativas, adeptas a gestos feitos e de fácil aprendizado. Contudo, o que está por detrás dessas considerações é o endosso da noção de que "as opções culturais das camadas populares são muito menores" (Souza, 2004, p. 6). Prevalece, assim, uma distinção entre "alta" e "baixa" cultura na qual o valor estético, 
pedagógico ou moral é trazido à tona como balizador de juízo final. Procede-se a um deslocamento das atenções para aspectos técnicos da prática popular massiva para o exercício de exclusão de valores culturais, no qual o grande vilão chamado "mercado" é convidado a ocupar o nó górdio sobre as danças na mídia.

Com intuito de deslocar o modo de olhar para as danças presentes nos meios de comunicação de massa, sem cair em axiomas apressados, empreenderei, a partir de agora, um esforço em demonstrar a relevância do estudo sobre as danças na mídia, alertando que tal feito, a princípio, deve ser destacado de suas contribuições para a estética filosófica ou o ensino formal de dança. Essa guinada se faz necessária porque o que torna as danças na mídia questionáveis, do ponto de vista da arte e das perspectivas puristas da cultura popular, é justamente aquilo que a faz interessante para uma investigação antropológica, já que seu valor não consiste no recrutamento de discussões presentes no campo artístico, nem na fixação de significados característicos que possam alinhavar a diversidade de danças encontradas na mídia.

O desafio consiste, então, em ramificar uma malha de considerações para que possamos amenizar a concepção fatalista sobre dança e meios de comunicação de massa, sem deixar de reconhecer a relevância dos estudos até aqui expostos. Com intuito provocativo, procedo à análise de apropriações e incorporações realizadas no meio popular urbano, partindo do pressuposto de que o sucesso da mídia não pode ser mensurado somente pela competência de seus agentes, já que depende muitíssimo da satisfação do público, que compreendo não ser totalmente controlado ou manipulado, como supõem os autores ancorados nos pressupostos da teoria crítica alemã.

De pronto, há que se reconhecer que o processo histórico se encarregou de amenizar os conflitos ideológicos que tanto marcaram o século $X X^{5}$, sobre os quais se fundamentaram os teóricos marxistas ao atribuírem um poder incomensurável aos meios de comunicação de massa. Em se tratando de Brasil, dispomos de pesquisas voltadas à demonstração de que o sucesso alcançado por danças como funk e "axé" e dança de rua na indústria cultural se deu mais à sua prévia existência e à disseminação de seus fazeres entre os setores populares no meio urbano que a uma suposta estratégia de uma elite detentora dos meios de comunicação (Bião, 1998; Guarato, 2008 e 2011; Vianna, 1988 e 1990). Nesse sentido, ao pesquisar a cultura do funk no Rio de Janeiro, o antropólogo Hermano Vianna constatou, em fins da década de 1980, a seguinte situação:

Os discos que mais fazem sucesso nos bailes, na maioria absoluta dos casos, não são lançados no Brasil. As emissoras de rádio e televisão quase não dão espaço para a música funk. Os jornais não anunciam os bailes que, apesar de tudo isso, permanecem lotados. O desejo por funk parece algo interno à comunidade carioca que o consome, sem depender da ajuda ou do incentivo de instituições externas (Vianna, 1990, p. 250).

Munidos desse ponto de vista, podemos sugerir que, diferentemente da proposta compartilhada por Adorno e Horkheimer, em casos como o supracitado, os

5 Refiro-me às diferentes correntes ideológicas, com destaque para socialismo marxista, anarquismo, nazismo, fascismo e capitalismo. Todas as teorias apresentaram modelos e caminhos positivados a serem percorridos para que seja alcançada uma sociedade idealizada. 
usuários interferem e produzem a demanda a ser atendida pelos meios massivos. Isso significa que existe um mercado de produção e consumo de dança forjado pelos populares antes mesmo de sua inserção na indústria da cultura. De todo modo, os adeptos mais fervorosos da concepção apocalíptica podem argumentar: "mas, uma vez inseridas na indústria cultural, essas danças assumem o aspecto mercadológico e passam a obedecer às normas dos detentores dos meios".

Considero tal assertiva correta, desde que estejamos dispostos a abrir mão da análise das experiências dos sujeitos envolvidos no processo. Entretanto, como pesquisador, procedo à compreensão sociocultural das relações humanas a partir dos sujeitos que as vivenciam e não daquilo que acredito que sejam suas experiências segundo epistemologias previamente disponíveis. E como hoje existe um complexo sistema de produção e consumo, impulsionado pelas tecnologias de informação e comunicação que ampliam as opções e possibilidades de decisão dos usuários/consumidores, seria incoerente imaginar que os processos de recepção daquilo que se encontra presente nos meios de comunicação de massa ocorram de modo passivo, como mera reprodução.

Majoritariamente, as danças presentes na indústria cultural são provenientes da cultura popular urbana. Entendo por cultura popular não uma forma de manifestação estática, isolada, separada de qualquer processo de assimilação, detentora de uma origem localizável e de uma tradição encerrada, mas sim como um conjunto de práticas culturais fortemente imbricadas em relações de apropriação, incorporação e reelaboração efetivadas e transmitidas no tempo presente, atravessada por interesses e expectativas de seus fazedores. Com essa perspectiva, cabe então ao pesquisador compreender as diversas recriações que as camadas populares fazem daquilo que lhes é evidenciado e ficar atento às descontinuidades de tais práticas.

Essa guinada de olhar consiste antes numa revisão de referenciais teóricos disponíveis que numa excepcionalidade deste pesquisador. Se retornarmos aos debates entre os teóricos da Escola de Frankfurt e nos alertarmos às considerações de Walter Benjamin, poderemos iniciar nosso municiamento epistemológico. De modo diverso à concepção dos formuladores do conceito de indústria cultural, Benjamin entende que o processo de reprodução não consiste numa cópia idêntica, assim como permitia inserir um conteúdo próximo a um público que dificilmente teria acesso a ele de outro modo. Nesse sentido, a reprodução aproxima indivíduo e obras, desfazendo o sentido "aurático" delas.

O que mais me interesse ressaltar das reflexões desse filósofo alemão neste texto é sua explicação sobre o processo de assimilação dos conteúdos reproduzidos por meio da indústria da cultura: "Na medida em que ela multiplica a reprodução, substitui a existência única da obra por uma existência serial. $E$, na medida em que essa técnica permite à reprodução vir ao encontro do espectador, em todas as situações, ela atualiza o objeto reproduzido" (Benjamin, 1994, p. 169). É nessa atualização que abala a tradição e promove leituras de que fala Benjamin que me aterei com mais afinco.

O processo detectado por Benjamin foi objeto de extensos estudos por parte dos intelectuais que formaram os Estudos Culturais. Em específico, destaco a noção de mediação, oferecida pelo crítico literário Raymond Williams como instrumento conceitual que permite perceber as diferentes formas de recepção. De acordo com 
esse autor, as realidades sociais não são sempre refletidas nos conteúdos transmitidos, ou seja, uma dança e sua estética não podem ser (ou sempre ser) entendidas segundo a ideia de reflexo (Williams, 1979). Dito de outra forma, uma dança que simula gestos que associamos ao ato sexual ou à violência não poder ser batizada como exemplo do que seus praticantes fazem em outros momentos de suas vidas; a reprodução de uma estética de dança nem sempre é acompanhada dos sentidos, do porquê se dança.

O abando da ideia de reflexo é ancorado pelo reconhecimento do processo de mediação que modifica o conteúdo daquilo que é reproduzido (Williams, 1979). Por esse viés, mesmo com a manutenção de alguns passos, modificam-se os significados do dançar e dos modos de execução, bem como dos lugares de exibição da dança. $O$ importante passa a ser não o que se recebe, mas como o recebido é usado. Isso quer dizer que os consumidores não devem ser analisados com base nos produtos midiáticos e comerciais que assimilam, desconsiderando-se os diferentes usos que deles se possa fazer6. Isso posto, a guinada consiste em deixar de perceber exclusivamente as formas das danças para adentrar ao estudo de quem, onde e porquê se dança.

Pelo processo de mediação, as realidades podem ser projetadas ou disfarçadas. Tanto as chamadas classes sociais dominantes quanto as populares não aceitam tudo que thes é apresentado; ambas rejeitam, excluem, reprimem, mesmo jogando com forças desiguais. O que impede o reconhecimento da atividade cultural quando imersa nos meios é a transformação da experiência em produto acabado, com formas fixas. Essa fixidez se expande para o território das relações socioculturais, insinuando estarem todas elas já definidas e formatadas. Ao contrário disso, acredito que os movimentos de apropriação não podem ser modulados porque estão sempre em processo, sendo experienciados, vividos e transformados durante um percurso.

Ao não negligenciarmos ou desqualificarmos as experiências em dança nos meios massivos, levamos em consideração que a vontade de dançar, de copiar e consumir o que é mostrado em mídias como televisão, filmes e video clips não decorre exclusivamente de arranjos empresariais. Aliado aos apelos midiáticos e mercadológicos, tem de haver reconhecimento de valores compartilhados nos processos de interação social, pois são esses valores que criam cadeias significativas que possibilitam a existência e manutenção de danças no contexto midiático. Nesse sentido, considerável volume de danças divulgadas pelos meios de comunicação possui adesão massiva por portar referências de mais fácil assimilação e por se aproximar do conhecimento de mundo e do estilo de vida da audiência que o consome.

Essa paralaxe sobre os meios de comunicação de massa não implica a defesa de uma guinada de cento e oitenta graus, a ponto de ingenuamente sugerir ineficácia do alcance da indústria cultural, como adverte o comunicólogo Jesús Martín-Barbero:

Não que não haja certos níveis de controle. Há sim, mas o controle nunca será na mesma medida em que os comerciantes acham que controlam. Eles precisam criar nas pessoas a sensação de que são compreendidas e estão satisfeitas, mas, na verdade, a sociedade mostra que as pessoas vivem desconcertadas, que não são compreendidas nem muito menos satisfeitas, senão a situação seria outra (Martín -Barbero, 2005, p. 246).

6 Também por esse viés, os conceitos de "práticas" e "astúcias" do antropólogo e historiador Michel de Certeau oferecem um interessante manancial teórico para designar os processos de apropriação cultural. Sobre o assunto, consultar a obra: Michel de Certeau. A invenção do cotidiano. 3. ed. Rio de Janeiro: Vozes, 1998. 
O mote da problematização que aqui proponho é que conceitos como "cultura de massa" e "meios de comunicação de massa" devem passar por uma revisão a cada estudo no qual são empregados. No Brasil do século XXI, dispomos de uma educação massificada, de editais públicos de fomento à dança que são meios massificados. Temos inclusive autores como Paulo Freire sendo replicados de modo massivo. E essa diversidade de produtos e informações disponíveis em grande escala não foi suficiente para garantir que consumidores reproduzissem seus conteúdos e, menos ainda, que suas premissas sejam reproduzidas, seguindo a cartilha de seus enunciadores. Por isso, não considero demonstrável o fato de que a inserção de informações nos meios massivos seja garantia suficiente de reprodução (em seu sentido pejorativo de passividade), sucesso e venda, não mais do que penso ser demonstrável a existência de uma pluralidade de usos e processos de apropriação sobre as informações neles veiculados.

Penso ser crucial diagnosticarmos que a área de marketing investe em produzir consumidores para produtos que prometem oferecer aquilo de que eles precisam, mas as necessidades formuladas pelo mercado não surgem no nada, elas partem de anseios e de desconfortos já sentidos. Nessa perspectiva, importa compreendermos o que as pessoas veem nos meios, o que pensam a partir do que viram, e não o controle sobre as pessoas, para que possamos compreender as "brechas" (Martín-Barbero, 2003). Essas brechas não acontecem nas mídias em si, mas com o que as pessoas procuram, criam, com suas expectativas sobre a mídia. Portanto, é "preciso entender que as pessoas não são idiotas" (Martín-Barbero, 2003) e que a ideia de que a mídia forja expectativas, desejos, sentimentos, satisfação aos receptores não é desprovida de razão, mas também não é feita somente dela. Percebo que ela não atua com tanto poder assim; certos fatores são assimilados, mas nem sempre da forma e com o conteúdo que são propostos.

Ao mesmo tempo, os meios massivos veiculam o popular ou elementos que podem vir a se tornar populares (Martín-Barbero, 2003, p. 322), tal como ocorreu na dança de rua com movimentos oriundos de outras danças: alguns passos foram mantidos, mas com mudanças nos significados do se dançar, no modo de execução e nos lugares de exibição (Guarato, 2008). Assim, olhando para a bibliografia que trata das danças presentes nos meios massivos, tenho a impressão de que o que impede o reconhecimento da atividade cultural nessas danças são as transformações da experiência de seus sujeitos em produtos acabados. Reconheço que as estratégias de mercado, assim como muitos discursos midiáticos, consideram as ações concluídas, tendendo a fixar formas, pressupondo relações, instituições e formações como definidas, não em transformação. A manutenção dessa concepção em estudos acadêmicos é o que torna a questão preocupante.

Ao historicizar o termo massa, Raymond Williams (1969) notou que tal nomenclatura surge acompanhada de outros conceitos, como "credulidade", "preconceitos de grupo", "vulgaridade de gosto e hábitos", resultando dessas associações uma concepção dedicada em classificar as massas como ameaça à cultura "qualificada". 
dulidade, volubilidade, preconceitos de grupo, vulgaridade de gosto e de hábitos. As massas, encaradas desse modo, constituíram perene ameaça para a cultura. Pensamento de massa, sugestão de massa, preconceito de massa, ameaçavam afogar o pensamento e o sentimento individual qualificado (Williams, 1969, p. 308).

Nessa direção, se alguma forma de dança veiculada nos meios de comunicação de massa, como o funk carioca, o "axé", o arrocha ou mesmo as danças de salão, ganhar algo, será a vitória da má dança, da vulgaridade e da mediocridade. Isso porque o sentido de massa é sempre empregado para remeter ao outro. Se partirmos do entendimento de que "não considero massa meus parentes, amigos, vizinhos, colegas, conhecidos; nenhum de nós age ou pode agir assim. As massas são sempre os outros" (Williams, 1969, p. 309), logo, não há como tornar palpável aquilo que apontamos, com certa facilidade, como massa; o que existem são maneiras de ver os outros como massa. Diante da generalidade do termo massa, é preciso examinar o sentido que damos à massa. Essa alteração no olhar para a cultura de massa desloca o problema do acesso e da aceitação do público a certas formas de dança para as preconcepções de ideias geradas a partir desses sucessos, ideias lançadas numa sociedade comandada por pessoas que renegam outras.

A ideia de massificação não pergunta às massas se elas querem ser massificadas; ela sintetiza a pluralidade. Na perspectiva analítica dos estudos culturais de Raymond Williams, o que é danoso para a sociedade não é a existência de meios de transmissão múltipla, eficientes e poderosos, mas a ideia de massas e de comunicação de massa, que são modos de funcionamento de uma sociedade que "relega a maioria de seus membros à condição de populaça" (Williams, 1969, p. 314). Com o exposto, conduzo a finalização deste texto, sugerindo certo esforço acadêmico a pesquisadores que de alguma forma lidam com a relação entre dança e meios de comunicação de massa, para perceberem como as ações corporais dançantes tidas como mero entretenimento atuam na formação humana no meio urbano, entrelaçando complexas redes de significado entre seus fazedores e o mundo que os cerca.

Se as danças na mídia não lidam com as preocupações do mundo artístico e suas orientações são de outra ordem, faz-se interessante averiguarmos esse fazer segundo outros referenciais que não os presentes no mundo da arte. A desqualificação das danças na mídia se dá porque as análises sobre código e mensagem costumam se ater aos produtos e não aos processos de interação entre os sujeitos envolvidos. Assim, as considerações tendem a ser mais políticas e morais do que das danças em si, enquanto um olhar antropológico propicia averiguar o que mobiliza as pessoas na busca por sentidos de suas danças quando inseridas nos meios massivos. Compartilho do entendimento do antropólogo social John Blacking, para quem

a dança como um fenômeno humano não pode ser propriamente entendida fora dos contextos de uso e dos mundos conceituais de seus usuários. Isso requer que a dança seja estudada transculturalmente, através de 'linguagens' cotidianas de diferentes culturas (Blacking, 1983, p. 92).

Em ambientes nos quais não existe uma dança para cada corpo, cada corpo usa as danças disponíveis para um fazer diferente. As mediações realizadas pelos usuá- 
rios podem denunciar arranjos improváveis, como a dança do passinho, afastando a crença de que é na diversidade de formas de dançar que se encontra a liberdade do corpo. Isso traz a possibilidade de olharmos como as pessoas fazem uso das danças disponíveis em seu circuito sociocultural em seus cotidianos.

A relevância de entender a dinâmica dos aprendizados culturais em condições específicas (Kroeber, 1917) permite arregimentarmos certos sentidos que edificam uma "dança comum" $\nabla$ por falta de um termo mais adequado $\otimes$ que dispõe de um fazer sistematizado de pensamento e ação, mas que não é algo inerente a todos. São pressupostos de uma elaboração de formas específicas no interior de uma forma geral que inclui gestos, vestimentas, movimentos, espaços, políticas, interesses, deslocamentos; ações iniciadas por sujeitos dentro de uma prática e que se tornam convenções ao estabelecer relações com o público que aceita ou aprende a lidar com essas danças.

Essa "dança comum" não se ancora num saber científico ou vinculado ao campo da dança como arte. Sua autoridade provém da empiria, da vida em sua decorrência. Enquanto mover-se é algo comum, o uso do corpo para fins de dança é um fazer que se aprende com pessoas que nos rodeiam, que, junto de passos e movimentos, trazem consigo um repertório de sentidos e anseios imersos em suas danças. Faz-se, portanto, relevante a investigação densa sobre essa dança comum, que não se limite a descrever e ajuizar sua execução ou processos de ensino/aprendizado através dos meios massivos. Para tanto, deve-se empreender uma revisão dessa distinção abandonada, entre uma mera reprodução aleatória $\nabla$ se é possível que isso ocorra $\nabla$ e modos de fazer no e com o cotidiano por sujeitos que reconhecem, avaliam e julgam a realidade que os cerca.

\section{Referências}

ADORNO, Theodor W. A indústria cultural. In: Gabriel Cohn (org.). Theodor Adorno: Sociologia. São Paulo: Ática, 1986, p. 92-99. (Coleção Grandes Cientistas Sociais, v. 54).

A televisão e os padrões da cultura de massa. In: ROSENBERG, Bernard; WHITE, David Manning (org.). Cultura de massa: as artes populares nos Estados Unidos. São Paulo: Cultrix, 1973, p. 546-562.

Indústria cultural e sociedade. São Paulo: Paz e Terra, 2002.

O fetichismo na música e a regressão da audição. In: Os Pensadores. São Paulo: Nova Cultural, 1996.

ADORNO, Theodor W; HORKHEIMER, Max. A indústria cultural: o esclarecimento como mistificação das massas. In: Dialética do esclarecimento. Rio de Janeiro: Zahar, 1983, p. 99-138.

BENJAMIN, Walter. Magia e técnica, arte e política. 7. ed. São Paulo: Brasiliense, 1994. 
BIÃO, Armindo. O obsceno em cena, ou o Tchan na boquinha da garrafa. Repertório Teatro \& Dança, Salvador, v. 1, n. 1, p. 23-26,1998.

BLACKING, John. Movement and meaning: dance in social antropological perspective. Dance Research, v. 1, n. 1, p. 89-99,1983.

CERTEAU, Michel de. A invenção do cotidiano. 3. ed. Rio de Janeiro: Vozes, 1998.

CLIFFORD, James. A experiência etnográfica: antropologia e literatura no século XX. Rio de Janeiro: UFRJ, 2011.

CÔRTES, Gustavo. Dança, Brasil: festas e danças populares. Belo Horizonte: Leitura, 2000.

GALLARDO, Jorge Sérgio Pérez; SBORQUIA, Silvia Pavesi. As danças na mídia e as danças na escola. Rev. Bras. Cienc. Esporte, Campinas, v. 23, n. 2, p. 105-118, 2002.

GUARATO, Rafael. O popular, os meios e a dança axé no interior das gerais. Textos Escolhidos de Cultura e Arte Populares, Rio de Janeiro, v. 8, n. 1, p. 107-123, 2011.

GUARATO, Rafael. Dança de rua: corpos para além do movimento. Uberlândia: Edufu, 2008.

HORKHEIMER, Max. Arte nuevo y cultura de masas. In: Teoria crítica. Barcelona: Barral, 1973, p. 115-137.

KATZ, Helena. A diferença entre arte e cultura. Jornal Urbano, São Paulo, 22 abr. 2009, p. 3.

Danças populares brasileiras. São Paulo: Rhodia, 1989.

KROEBER, Alfred Louis. The Superorganic. American Anthropologist, New Series, v. 19, n. 2, p. $163-213,1917$.

MARQUES, Isabel A. Linguagem da dança: arte e ensino. São Paulo: Digitexto, 2010.

MARTÍN-BARBERO, Jesús. Dos meios às mediações: comunicação, cultura e hegemonia. 2. ed. Rio de Janeiro: UFRJ, 2003.

Entrevista. In: MARKUN, Paulo (org.). O melhor do Roda Viva: o mais antigo e respeitado programa de entrevistas da TV. São Paulo: Conex, 2005, p. 245-254.

MONTEIRO, Marianna. Dança popular: espetáculo e devoção. São Paulo: Terceiro Nome, 2011. 
RODRIGUES, Graziela. Bailarino-pesquisador-intérprete: processo de formação. 2. ed. Rio de Janeiro: Funarte, 2005.

SANTOS, Inaicyra. Da tradição africana brasileira a uma proposta pluricultural de dança-arte-educação. São Paulo, 1996. Tese (Doutorado) - Faculdade de Educação, Universidade de São Paulo.

SILVA, Rafael Cordeiro. Cultura, dominação e emancipação: dois pontos de vista. InterAções - Cultura e Comunidade, Uberlândia, v. 1, n. 1, p. 23-38, 2006.

SILVA, Renata Lima. Corpo limiar e encruzilhada: processo de criação em dança. Goiânia: UFG, 2012.

SOUZA, Maria Inês Galvão. Arte, cultura e sociedade: uma rede intrigante para algumas reflexões sobre a dança. In: VIII ENFEFE, 2004. Anais do Encontro Fluminense de Educação Física Escolar, Niterói. Disponível em: <http://grupoanima.org/arte-cultura-e-sociedade-uma-rede-intrigante-para-algumas-reflexoes-sobre-a-danca/>. Acesso em: 10 maio 2008.

TOMAZZONI, Airton. Lições de dança no baile da pós-modernidade: corpos (des)governados na mídia. Porto Alegre, 2009. Tese (Doutorado) - Faculdade de Educação, Universidade Federal do Rio Grande do Sul.

VIANNA, Hermano. Funk e cultura popular carioca. Estudos Históricos, Rio de Janeiro, v. 3, n. 6. p. 244-253, 1990. O mundo funk carioca. Rio de Janeiro: Jorge Zahar, 1988.

WILLIAMS, Raymond. Cultura e sociedade - 1780-1950. São Paulo: Companhia Editora Nacional, 1969.

WILLIAMS, Raymond. Marxismo e literatura. Rio de Janeiro: Zahar Editores, 1979.

Recebido em: 26/09/2016

Aprovado em: 11/11/2016 